\title{
Difference in clinical presentation between women and men in incident primary Sjögren's syndrome
}

\author{
Jorge I. Ramírez Sepúlveda', Marika Kvarnström', Susanna Brauner ${ }^{2}$, Chiara Baldini ${ }^{3}$ and Marie Wahren-Herlenius ${ }^{1 *}$ (D)
}

\begin{abstract}
Background: A more severe disease phenotype has been reported in men compared to women in several rheumatic diseases. However, studies have not conclusively established sex-related clinical features in primary Sjögren's syndrome (pSS). In this study, we therefore investigated the clinical presentation of pSS in women and men at diagnosis.

Methods: Incident, treatment naïve patients $(n=199)$ during a 5-year period in a specified area were prospectively included and examined for items of classification criteria for pSS as well as extraglandular manifestations (EGM). Serum was sampled at the time of diagnosis and anti-Ro52/SSA levels were measured by ELISA. Replication of significant findings was confirmed in an independent cohort of pSS patients $(n=377)$, and meta-analysis was performed.

Results: An increased frequency of extraglandular manifestations in men was observed and replicated $(p=0.05$, $p=0.0003$, and $p_{\text {meta }}=0.002$. This related to pulmonary involvement, vasculitis, and lymphadenopathy being more common in men, for whom a lower age at diagnosis was observed in the exploratory cohort. Additionally, SSA-positive male patients had significantly higher levels of anti-Ro52 levels than their female counterparts in sera available for analysis $(p=0.02)$.

Conclusions: Our analysis of two independent cohorts of incident pSS demonstrates that the presence and number of EGM are significantly more frequent among men with pSS than women at diagnosis. Importantly, around half of the male patients presented with more than one EGM at diagnosis, supporting the conclusion that pSS in men represents a more severe form of disease, regardless of the lower risk for men to develop pSS.
\end{abstract}

Keywords: Sjögren's syndrome, Autoimmunity, Extraglandular manifestations, Sex differences, Disease severity

\section{Background}

Primary Sjögren's syndrome (pSS) is an autoimmune rheumatic disease in which chronic inflammation results in progressive destruction of exocrine glands, primarily the salivary and lacrimal glands, leading to symptoms of dryness [1]. Extraglandular manifestations (EGM) such as interstitial lung disease, cutaneous vasculitis, and lymphadenopathy are present in a subset of patients characterized by a more systemic phenotype. As part of their autoimmune disease, pSS patients have a changed pattern in B-cell maturation and proliferation, resulting in hypergammaglobulinemia and autoantibodies against the antigens

\footnotetext{
* Correspondence: marie.wahren@ki.se

${ }^{1}$ Unit of Experimental Rheumatology, Department of Medicine, Karolinska Institutet, Karolinska University Hospital, SE-171 76 Stockholm, Sweden Full list of author information is available at the end of the article
}

Ro/SSA (Ro52 and Ro60) and La/SSB [1-5]. Recently, autoantibodies against the Ro52 antigen were shown to functionally inhibit ubiquitination mediated by the E3 ligase and to correlate with disease activity [6-8].

As for many autoimmune diseases [9], the majority of patients with pSS are women, with an estimated female to male ratio of $9-14$ to 1 [9-11]. Differential immune regulation [12-14], X-chromosome gene dosage effects $[15,16]$, sex hormones [17-19], and sex-specific exposure to environmental factors $[20,21]$ have all been implicated to contribute to these sex differences. In addition to the difference in disease susceptibility, the clinical manifestations of autoimmune diseases can also differ between the sexes.

Interestingly, more severe forms of disease have been suggested to develop in male than in female patients for 
several autoimmune disorders. In SLE, males have been reported to have more severe clinical manifestations than females [22-27]. The tissue damage caused by the disease, as measured by the Systemic Lupus International Collaborating Clinics/American College of Rheumatology Damage Index (SDI), is more pronounced in men [28], and the survival rate for male patients with SLE is lower than their female counterparts [29]. In systemic sclerosis, male sex is associated with decreased survival, higher rates of interstitial lung disease, and diffuse cutaneous disease [30]. Also in patients affected by multiple sclerosis (MS), male sex is considered to be a poor prognostic factor, as it is linked to early disability and faster disease progression [31].

With regard to pSS, a handful of studies have addressed the clinical and serological differences between female and male patients without reaching a clear consensus; primarily due to differences in classification criteria, study design, patient sample sizes, and ethnic heterogeneity [32-39]. Further, the cohorts often represent small and selected groups of patients. In the present study, we therefore assessed the clinical and immunological profile of incident cases of female and male pSS patients in a population-based cohort to determine if the clinical and serological presentation of the disease differs between sexes and replicated the findings in an independent cohort.

\section{Methods}

\section{Patients}

The exploration cohort $(n=199 ; 186$ women and 13 men) was established in a population-based manner and represents an estimated $>95 \%$ of patients investigated for and diagnosed with primary Sjögren's syndrome within the defined geographic catchment area (Stockholm County, Sweden) and time period of 5 years (from 1 January 2007 to 31 December 2011) [10]. The patients were referred to and diagnosed at the Department of Rheumatology at the Karolinska University Hospital, Stockholm, Sweden, and more than $90 \%$ of the patients were examined by the same rheumatologist (MK) [10]. All patients were classified according to the 2002 revised American-European Consensus Criteria (AECC) [40] for primary Sjögren's syndrome, and patients fulfilling criteria for other rheumatic or autoimmune diseases such as SLE or rheumatoid arthritis were excluded. The investigation included questions regarding sicca symptoms, Schirmer's test, unstimulated whole salivary flow test (USWF), and serological analysis of Ro/SSA and La/ SSB autoantibodies by a clinical immunology routine laboratory using Line blot (2007-2009) or Bio-Plex (2010-2011) assays. A salivary gland biopsy was performed if required for a complete diagnostic investigation. A clinical examination was performed at the time of diagnosis, evaluating general health and systematically recording features of pSS according to a protocol focusing on extraglandular manifestations (EGM) [10]. We defined EGM as typical organ manifestations from our clinical experience with pSS patients and also required that they should have been described previously in the literature. These EGM correspond to those later defined in the European League Against Rheumatism (EULAR) Sjögren's syndrome disease activity index (ESSDAI) published in 2010 [41]. We regarded the symptoms and organ manifestations in each individual as EGM of pSS if no other explanation was present. An abnormal computer tomography (CT) of the lungs was required for the diagnosis of interstitial lung disease. Exclusion of other autoimmune diseases was made based on physical examination by the rheumatologist, results from blood samples including immunology testing and if necessary $\mathrm{X}$-ray and other investigations like skin biopsy and neurography. A serum sample taken at the time of diagnosis was available for 146 patients (female $n=136$, male $n=10$ ). The study was approved by the Regional Ethics Committee Stockholm North, and all participants gave written informed consent.

Replication was performed in an incident cohort of patients with Sjögren's syndrome $(n=377 ; 368$ women and 9 men) diagnosed at the Rheumatology Unit, University Hospital of Pisa, Pisa, Italy, by the same procedures as described above. The cohort was represented by patients referred to the Rheumatology Unit mainly from central Italy for investigation of pSS during an 8year period (from 1 January 2007 to 1 January 2015). Caucasian patients represented $>95 \%$ of the cases. More than $90 \%$ of the patients were examined by the same rheumatologist (CB). Similarly to the Swedish cohort, all patients were classified according to the 2002 revised American-European Consensus Criteria (AECC). All patients gave informed consent for all procedures, which were carried out with local ethics committee approval (Comitato di Bioetica, University of Pisa).

\section{Anti-Ro52/SSA ELISA}

Furthermore, ELISA for anti-Ro52 autoantibodies was performed as previously described [42-45]. Briefly, high binding 96-well plates (Nunc) were coated with $1 \mu \mathrm{g}$ of recombinant full-length Ro52 protein per well, diluted in carbonate buffer ( $\mathrm{pH}$ 9.6). Before use, the plates were blocked with phosphate-buffered saline (PBS) $/ 0.05 \%$ Tween $/ 5 \%$ milk powder for $2 \mathrm{~h}$. Sera diluted in Tween-PBS/1\% milk powder were added and incubated for $2 \mathrm{~h}$ at room temperature. Autoantibody binding was detected with an alkaline phosphatase-conjugated rabbit anti-human IgG antibody 1:2000 (Dakopatts), which was incubated for $2 \mathrm{~h}$ at room temperature. Finally, binding was 
visualized using phosphatase substrate tablets (Sigma) and measured at $405 \mathrm{~nm}$ absorbance. A high antiRo52 titer serum was used as standard with serial dilutions for calculation of arbitrary units of antibody levels.

\section{Statistical analysis}

For statistical comparisons of categorical variables between groups, the Chi-square test for $2 \times 2$ contingency tables was performed; Fisher's exact test was employed if the observed frequency of any given cell was $<5$. Numerical variables were analyzed by the Mann-Whitney $U$ test. The statistical analysis was done using Prism GraphPad 6. For meta-analyses of data from the two pSS cohorts, the heterogeneity between both studies was measured as $I^{2}$. When $I^{2}$ was below 0.5, a fixed effect model was employed; otherwise, in cases of higher heterogeneity of data, the random effect model was considered. Meta-analyses were performed with Review Manager (RevMan) software Version 5.3. (Copenhagen: The Nordic Cochrane Centre, The Cochrane Collaboration, 2014). A $p$ value $<0.05$ was considered significant.

Table 1 Basic characteristics and objective pSS classification items of the patients in the exploratory cohort

\begin{tabular}{|c|c|c|c|}
\hline & $\begin{array}{l}\text { Women } \\
n=186 \\
\% \text { (frequency) }\end{array}$ & $\begin{array}{l}\text { Men } \\
n=13 \\
\% \text { (frequency) }\end{array}$ & $p$ value \\
\hline \multicolumn{4}{|l|}{ Basic characteristics } \\
\hline Sex & $93 \%(186 / 199)$ & $7 \%(13 / 199)$ & $<0.0001$ \\
\hline $\begin{array}{l}\text { Age at diagnosis, years } \\
(\text { mean } \pm \mathrm{SD})\end{array}$ & $56 \pm 14$ & $46 \pm 12$ & 0.01 \\
\hline \multicolumn{4}{|l|}{ Item III. Ocular signs ${ }^{\mathrm{a}}$} \\
\hline $\begin{array}{l}\text { Schirmer's test } \\
(\leq 5 \mathrm{~mm} \text { in } 5 \mathrm{~min})\end{array}$ & $70 \%(129 / 185)$ & $77 \%(10 / 13)$ & 0.58 \\
\hline \multicolumn{4}{|l|}{ Item IV. Histopathology ${ }^{a}$} \\
\hline \multicolumn{4}{|l|}{ Minor salivary gland biopsy ${ }^{a}$} \\
\hline Performed & $85 \%(158 / 185)$ & $92 \%(12 / 13)$ & 0.49 \\
\hline $\begin{array}{l}\text { Positive } \\
\text { (focus score } \geq 1 \text { ) }\end{array}$ & $95 \%(149 / 157)$ & $83 \%(10 / 12)$ & 0.10 \\
\hline \multicolumn{4}{|c|}{ Item V. Salivary gland involvement ${ }^{a}$} \\
\hline UWSF $^{b}$ & $78 \%(145 / 186)$ & $77 \%(10 / 13)$ & 0.93 \\
\hline \multicolumn{4}{|l|}{ Item VI. Autoantibodies ${ }^{a}$} \\
\hline Positive (SSA and/or SSB) & $55 \%(100 / 183)$ & $54 \%(7 / 13)$ & 0.96 \\
\hline SSA positive & $53 \%(97 / 184)$ & $46 \%(6 / 13)$ & 0.65 \\
\hline SSB positive & $30 \%(55 / 184)$ & $33 \%(4 / 12)$ & 0.80 \\
\hline
\end{tabular}

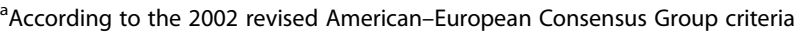
for Sjögren's syndrome

bUnstimulated whole salivary flow, $\leq 1.5 \mathrm{ml}$ in $15 \mathrm{~min}$

Bold values indicate statistically significant findings $(p<0.05)$

\section{Results}

Basic characteristics and AECC items in female and male patients at diagnosis of Sjögren's syndrome

A population-based cohort of incident cases of pSS ( $n=199$; 93\% women and 7\% men) (Table 1) was explored for potential differences in presentation between female and male patients. Among basic characteristics, we found that male patients were significantly younger at diagnosis, namely, 46 \pm 12 years in male patients compared to $56 \pm 14$ years for female patients (mean $\pm 95 \% \mathrm{CI} ; p=0.01$ ). Notably, $67 \%$ of the women were diagnosed after the age of 50 , which is commonly used as an approximation for menopause.

The frequency of items included in the 2002 AECC for Sjögren's syndrome was assessed. No significant differences in either subjective or objective ocular and oral signs were observed between female and male patients (Table 1). Salivary and lacrimal gland function was assessed by UWSF and Schirmer's test, respectively, with no significant differences in secretory capacities observed. Approximately, 90\% of both women and men had undergone salivary gland biopsy, with no significant difference in the frequencies of a positive result (Table 1), or degree of inflammation as measured by the focus score (data not shown). In summary, this indicates that female and male patients fulfill items III, IV, and V of the diagnostic criteria for pSS in a similar fashion.

\section{Autoantibodies in female and male patients}

SSA and SSB autoantibodies in serum were analyzed by a clinical routine diagnostic laboratory with no apparent difference in frequency of a positive result between female and male patients (Table 1). Since autoantibody levels were not quantified by the clinical laboratory, we performed a specific anti-SSA/Ro52 ELISA using purified recombinant antigen and sera taken at the time of diagnosis to evaluate whether autoantibody levels differed among SSA-positive female and male patients. Interestingly, we found that the SSA-positive men presented with significantly higher levels of anti-Ro52 antibodies than the women $(p=0.02)$ (Fig. 1), although the number of sera available for analysis was low (women $n=61$ and men $n=5$, respectively).

\section{Differences in extraglandular manifestations among women and men diagnosed with pSS}

Previous studies indicate that approximately $40 \%$ of patients with pSS experience some degree of extraglandular involvement [46]. The presence and number of EGM in our exploratory cohort of pSS patients were assessed at diagnosis (Table 2). Pulmonary involvement in terms of interstitial lung disease $(p=$ $0.004)$, as well as cutaneous vasculitis $(p=0.007)$, were significantly more frequent in men. The occurrence of other common or specific clinical 


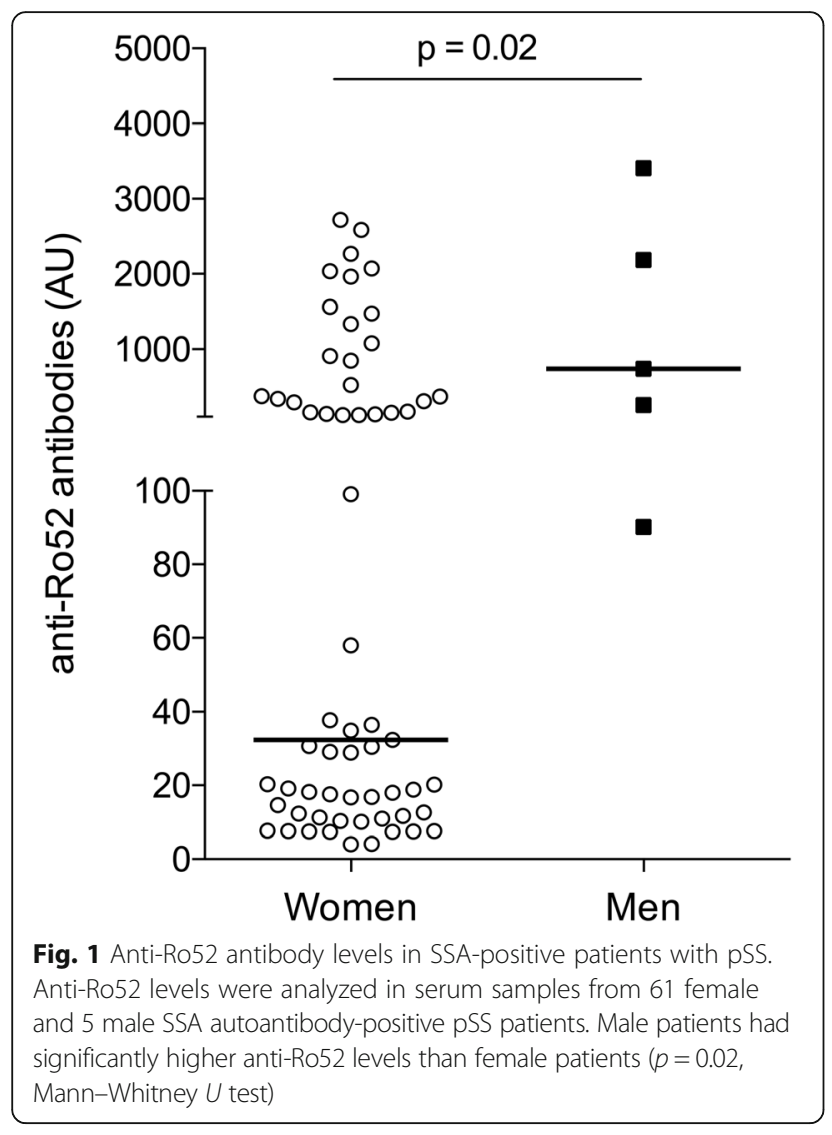

manifestations of Sjögren's syndrome was also investigated, but no significant differences between men and women were observed (Table 3 ).

We further analyzed whether the frequency and number of concomitant extraglandular manifestations differed between the sexes, as a sign of more severe disease. We observed a trend towards more male patients presenting with at diagnosis $(p=0.10)$, and interestingly, among those men that had at least one EGM (EGM+), the number of concomitant extraglandular manifestations was significantly higher than in the female group $(p=0.04)$ (Table 2$)$.

\section{Replication and meta-analysis in an independent cohort}

To validate our observations, replication and metaanalysis were performed for parameters displaying a skewed frequency between male and female patients (Table 4). The cut-off for selecting parameters for replication and meta-analysis was set at $p=0.25$, to allow investigation of trends that had not reached statistical significance in the first cohort. Notably, interstitial lung disease, cutaneous vasculitis, and both presence of and higher number of concomitant extraglandular manifestations were confirmed as parameters more frequently observed in men at diagnosis with pSS than in women being diagnosed with the disease (Table 4). Further, the trends observed for alveolitis, lymphadenopathy, and recurrent fever were confirmed as significant by the meta-analysis $(p=0.01, p$ $=0.004$, and $p=0.0008$, respectively) (Table 4). The replication cohort and meta-analysis also confirmed the higher frequency of EMG in men, as well as more concomitant EGM in EGM+ men (Table 4).

\section{Discussion}

In this study, we provide evidence that there are differences, not only in incidence, but also in clinical presentation between women and men with pSS at the time of diagnosis. We explored sex-differences in a population-based cohort of incident pSS and used an independent cohort to confirm observations. Our results reveal a more severe disease phenotype in men at diagnosis. In addition, the immune activity represented by autoantibodies against the SSAcomponent Ro52 showed significantly higher levels of these specific antibodies in SSA-positive male compared to female patients.

We found that EGM are more common in male than in female patients at the time of pSS diagnosis. In our population-based cohort, the number of EGM among $\mathrm{EGM}+$ patients was significantly higher in male than that in female patients, which was very close to significant in the replication cohort. A meta-analysis confirmed that the presence of EGM as well as number of EGM is more common in men with pSS. Similar trends have been previously reported for prevalent pSS, although statistical significance has been difficult to obtain due to the small number of men in the studies [32, 38, 47].

In our study, the frequencies of specific EGM also differed significantly between women and men. Interstitial lung disease and cutaneous vasculitis were significantly more common in men in our population-based cohort, and a similar trend was observed for interstitial lung disease in the replication cohort, resulting in a significant difference in the meta-analysis. Similarly, lymphadenopathy and recurrent fever were significantly more common in the replication cohort while it only shows a tendency in the exploratory cohort. Alveolitis displayed a strong tendency in the exploratory cohort which was confirmed after the meta-analysis, though the observation should be interpreted with caution considering the low numbers. A higher frequency of pulmonary involvement in male patients has been suggested by previous studies [34, 37], though statistical significance was not reached in these investigations. Also, lymphadenopathy has been associated with male sex [36, 37, 39]. In all, similar trends for higher frequencies of specific EGM are found in male patients. It is important to point out that no EGM was significantly more frequent in the female patients in either cohort in our study. In summary, our 
Table 2 Frequency of extraglandular manifestations in female and male pSS patients in the exploratory cohort

\begin{tabular}{|c|c|c|c|c|}
\hline & $\begin{array}{l}\text { pSS all } \\
(n=199) \\
\% \text { (frequency) }\end{array}$ & $\begin{array}{l}\text { Women } \\
(n=186) \\
\% \text { (frequency) }\end{array}$ & $\begin{array}{l}\text { Men } \\
(n=13) \\
\% \text { (frequency) }\end{array}$ & $p$ value \\
\hline Presence of EGM & $30 \%(53 / 197)$ & $25 \%(47 / 185)$ & $46 \%(6 / 13)$ & 0.10 \\
\hline No. of EGM (mean \pm SD) & $0.34 \pm 0.64$ & $0.30 \pm 0.57$ & $0.85 \pm 1.21$ & 0.05 \\
\hline $\begin{array}{l}\text { No. of EGM in EGM+ patients } \\
\text { (mean } \pm \text { SD) }\end{array}$ & $1.26 \pm 0.59$ & $1.19 \pm 0.45$ & $1.83 \pm 1.17$ & 0.04 \\
\hline \multicolumn{5}{|l|}{ Extraglandular manifestations ${ }^{a}$} \\
\hline \multicolumn{5}{|l|}{ Articular } \\
\hline Arthritis & $14 \%(28 / 197)$ & $14 \%(26 / 184)$ & $15 \%(2 / 13)$ & 1.00 \\
\hline \multicolumn{5}{|l|}{ Pulmonary } \\
\hline Interstitial lung disease & $1 \%(2 / 196)$ & $0 \%(0 / 183)$ & $15 \%(2 / 13)$ & 0.004 \\
\hline Alveolitis & $0.5 \%(1 / 197)$ & $0 \%(0 / 184)$ & $8 \%(1 / 13)$ & 0.07 \\
\hline \multicolumn{5}{|l|}{ Renal } \\
\hline Interstitial nephritis & $0.5 \%(1 / 197)$ & $0.5 \%(1 / 184)$ & $0 \%(0 / 13)$ & 1.00 \\
\hline \multicolumn{5}{|l|}{ Cutaneous } \\
\hline Cutaneous vasculitis & $4 \%(7 / 195)$ & $2 \%(4 / 182)$ & $23 \%(3 / 13)$ & 0.007 \\
\hline \multicolumn{5}{|l|}{ Neurological } \\
\hline Polyneuropathy & $4 \%(8 / 195)$ & $4 \%(7 / 182)$ & $8 \%(1 / 13)$ & 0.43 \\
\hline Mononeuritis & $0.5 \%(1 / 197)$ & $0.5 \%(1 / 184)$ & $0 \%(0 / 13)$ & 1.00 \\
\hline CNS involvement & $1 \%(2 / 197)$ & $1 \%(2 / 184)$ & $0 \%(0 / 13)$ & 1.00 \\
\hline \multicolumn{5}{|l|}{ Constitutional } \\
\hline Recurrent fever & $7 \%(14 / 197)$ & $7 \%(12 / 184)$ & $15 \%(2 / 13)$ & 0.23 \\
\hline \multicolumn{5}{|l|}{ Lymphadenopathy } \\
\hline Enlarged lymph nodes & $1 \%(4 / 197)$ & $2 \%(3 / 184)$ & $8 \%(1 / 13)$ & 0.24 \\
\hline \multicolumn{5}{|l|}{ Muscular } \\
\hline Myositis & $2 \%(3 / 197)$ & $0.5 \%(1 / 184)$ & $0 \%(0 / 13)$ & 1.00 \\
\hline
\end{tabular}

${ }^{a}$ Extraglandular manifestations evaluated to estimate the EULAR Sjögren's syndrome disease activity index (ESSDAI) Bold values indicate statistically significant findings $(p<0.05)$

data establishes that men present with a more severe disease phenotype with more EMG at the time of diagnosis of pSS.

No major differences were observed for the lacrimal and salivary gland function between women and men with pSS in either cohort. The serological investigation of the pSS patients revealed that SSA-positive men have significantly higher levels of anti-Ro52 at diagnosis than

Table 3 Frequency of other common clinical manifestations of pSS

\begin{tabular}{llll}
\hline & $\begin{array}{l}\text { Women } \\
n=186 \\
\% \text { (frequency) }\end{array}$ & $\begin{array}{l}\text { Men } \\
n=13 \\
\% \text { (frequency) }\end{array}$ & $p$ value \\
\hline $\begin{array}{llll}\text { Raynaud's phenomenon } \\
\begin{array}{l}\text { Major salivary gland } \\
\text { swelling }\end{array}\end{array}$ & $10 \%(38 / 181)$ & $15 \%(2 / 13)$ & 1.00 \\
Cryoglobulinemia & $0 \%(0 / 186)$ & $0 \%(0 / 13)$ & 0.63 \\
Lymphoma & $0 \%(0 / 186)$ & $0 \%(0 / 13)$ & - \\
\hline
\end{tabular}

women, and of note, the patient with the highest autoantibody levels was a man. Although this finding can help explain the increased severity of the disease in men, the few sera available for analysis should be noted. Further studies with larger sample sizes might be able to definitely establish a marked serological difference between female and male patients. Serological investigations performed in previous studies show considerable discrepancies between the frequencies of anti-Ro/SSA positivity among the male patients. Some papers highlight significant serological differences between the sexes with a tendency for men to be less frequently seropositive [34-36, 38], but the antibody levels in seropositive individuals are rarely compared. However, Drosos et al. [36] reported that female patients have higher anti-Ro levels than males. The different observations may relate to the time point of serum sampling, as it is possible that more women develop higher autoantibody levels with disease progression. The differences between studies could potentially also depend on the assay used for 
Table 4 Replication and meta-analysis of manifestations with different frequencies among female and male patients with pSS

\begin{tabular}{|c|c|c|c|c|c|c|c|}
\hline & \multicolumn{3}{|c|}{ Ramírez Sepúlveda et al. } & \multicolumn{3}{|l|}{ Baldini et al. } & \multirow{2}{*}{$\begin{array}{l}\text { Meta-analysis } \\
p \text { value }\end{array}$} \\
\hline & $\begin{array}{l}\text { Women } \\
(n=186) \\
\% \text { (frequency) }\end{array}$ & $\begin{array}{l}\text { Men } \\
(n=13) \\
\% \text { (frequency) }\end{array}$ & $p$ value & $\begin{array}{l}\text { Women } \\
(n=368) \\
\% \text { (frequency) }\end{array}$ & $\begin{array}{l}\text { Men } \\
(n=9) \\
\% \text { (frequency) }\end{array}$ & $p$ value & \\
\hline Age at diagnosis & $56 \pm 14$ & $46 \pm 12$ & 0.01 & $51 \pm 15$ & $53 \pm 13$ & 0.86 & 0.07 \\
\hline Positive MSG biopsy ${ }^{\mathrm{a}}$ & $95 \%(149 / 157)$ & $83 \%(10 / 12)$ & 0.10 & $93 \%(293 / 315)$ & $100 \%(8 / 8)$ & 0.43 & 0.30 \\
\hline Presence of $E G M^{b}$ & $25 \%(47 / 185)$ & $46 \%(6 / 13)$ & 0.10 & $56 \%(205 / 368)$ & $100 \%(9 / 9)$ & 0.006 & 0.005 \\
\hline No. of $\mathrm{EGM}^{c}$ & $0.30 \pm 0.57$ & $0.85 \pm 1.21$ & 0.05 & $1.11 \pm 1.39$ & $2.89 \pm 1.62$ & 0.0003 & 0.002 \\
\hline No. of EGM in EGM + ${ }^{c}$ & $1.19 \pm 0.45$ & $1.83 \pm 1.17$ & 0.04 & $1.89 \pm 1.16$ & $2.67 \pm 1.41$ & 0.06 & 0.04 \\
\hline Interstitial lung disease & $0 \%(0 / 183)$ & $15 \%(2 / 13)$ & 0.004 & $9 \%(32 / 368)$ & $22 \%(2 / 9)$ & 0.19 & 0.002 \\
\hline Alveolitis & $0 \%(0 / 184)$ & $8 \%(1 / 13)$ & 0.07 & $2 \%(6 / 368)$ & $0 \%(0 / 9)$ & 1.00 & 0.01 \\
\hline Cutaneous vasculitis & $2 \%(4 / 182)$ & $23 \%(3 / 13)$ & 0.007 & $10 \%(38 / 368)$ & $11 \%(1 / 9)$ & 1.00 & 0.03 \\
\hline Lymphadenopathy & $2 \%(3 / 184)$ & $8 \%(1 / 13)$ & 0.24 & $37 \%(138 / 367)$ & $89 \%(8 / 9)$ & 0.003 & 0.004 \\
\hline Recurrent fever & $7 \%(12 / 184)$ & $15 \%(2 / 13)$ & 0.23 & $18 \%(66 / 368)$ & $67 \%(6 / 9)$ & 0.002 & 0.0008 \\
\hline
\end{tabular}

MSG minor salivary gland biopsy

${ }^{a}$ Focus score $\geq 1$

bxtraglandular manifestations evaluated to estimate the EULAR Sjögren's syndrome disease activity index (ESSDAI)

c (mean \pm SD)

Bold values indicate statistically significant findings $(p<0.05)$

autoantibody testing and the presence of Ro60 and Ro52 antigens, respectively. Notably, Ro52 antibodies have been associated with pulmonary disease, particularly interstitial lung disease and pulmonary fibrosis [48, 49], which we also observed more frequently in men from our cohort.

The strength of our investigation is that the studied exploration cohort was generated in a population-based manner representing approximately $95 \%$ of all incident cases in the specific geographical area during the 5-year period during which the cohort was established [10]. By this approach, selection bias was avoided. Also, more than $90 \%$ of the patients were examined and diagnosed by the same clinician, diminishing variation in assessment procedures and evaluation [10]. An additional strength of the study is that an independent cohort of incident pSS is used to verify observations. Around $90 \%$ of patients were seen by one specific clinician also in this cohort. Noteworthy, the replication cohort was not populationbased, potentially explaining some of the differences observed between the cohorts. The catchment and inclusion of patients in the replication cohort might have been more delayed than in the exploratory cohort, which could account for higher numbers of EGM. Despite this, men from the replication cohort still showed a more severe disease phenotype.

More than nine out of ten patients with pSS are women, and an inherent weakness of studies of sexdifferences of pSS is thus the smaller number of men in any given cohort. This is also the main drawback of the present study, despite including all cases in a densely populated defined geographical area during a 5-year period and using a replication cohort.

\section{Conclusions}

In conclusion, the clinical data from our two-cohort pSS study highlights differences in the presentation of the disease between women and men. Despite the fact that men are less prone to develop pSS, this study demonstrates that, at the time of diagnosis, male patients have a more severe disease than females with more EGMs. This suggests that the pathogenic mechanisms of pSS may vary between women and men, and that medical interventions should aim to approach this disease in a sexspecific manner.

\section{Acknowledgements}

We thank Amina Ossoinak and Vijole Ottosson for excellent technical support.

Funding

The study was supported by grants from the Swedish Research Council (Dnr 2012-2148), the Heart-Lung Foundation, the Stockholm County Council, Karolinska Institutet, the Swedish Rheumatism association, and the King Gustaf the V:th 80-year foundation.

\section{Availability of data and materials \\ Not applicable.}

\section{Authors' contributions}

All authors met the criteria for authorship. JRS and MWH designed the study, MK, CB, and JIRS acquired the data which was analyzed and interpreted by JIRS, MK, SB, CB, and MWH. JIRS and MWH wrote the manuscript and all authors participated in revision until its final stage. All authors read and approved the final manuscript.

\section{Competing interests}

The authors declare that they have no competing interests.

Consent for publication

Not applicable. 


\section{Ethics approval and consent to participate}

The study was approved by the Regional Ethics Committee Stockholm North and the Comitato di Bioetica, University of Pisa. All participants gave written informed consent.

\section{Publisher's Note}

Springer Nature remains neutral with regard to jurisdictional claims in published maps and institutional affiliations.

\section{Author details}

'Unit of Experimental Rheumatology, Department of Medicine, Karolinska Institutet, Karolinska University Hospital, SE-171 76 Stockholm, Sweden. ${ }^{2}$ Department of Clinical Neuroscience, Karolinska Institutet, Karolinska University Hospital, Stockholm, Sweden. ${ }^{3}$ Rheumatology Unit, University of Pisa, Pisa, Italy.

Received: 24 January 2017 Accepted: 25 April 2017

Published online: 12 May 2017

\section{References}

1. Wahren-Herlenius M, Dorner T. Immunopathogenic mechanisms of systemic autoimmune disease. Lancet. 2013;382:819-31.

2. Halse AK, Marthinussen MC, Wahren-Herlenius M, Jonsson R. Isotype distribution of anti-Ro/SS-A and anti-La/SS-B antibodies in plasma and saliva of patients with Sjogren's syndrome. Scand J Rheumatol. 2000:29:13-9.

3. Ottosson L, Hennig J, Espinosa A, et al. Structural, functional and immunologic characterization of folded subdomains in the Ro52 protein targeted in Sjogren's syndrome. Mol Immunol. 2006;43:588-98.

4. Pourmand N, Wahren-Herlenius M, Gunnarsson I, et al. Ro/SSA and La/SSB specific IgA autoantibodies in serum of patients with Sjogren's syndrome and systemic lupus erythematosus. Ann Rheum Dis. 1999;58:623-9.

5. Salomonsson S, Wahren-Herlenius M. Local production of Ro/SSA and La/ SSB autoantibodies in the target organ coincides with high levels of circulating antibodies in sera of patients with Sjogren's syndrome. Scand J Rheumatol. 2003:32:79-82.

6. Espinosa A, Hennig J, Ambrosi A, et al. Anti-Ro52 autoantibodies from patients with Sjogren's syndrome inhibit the Ro52 E3 ligase activity by blocking the E3/E2 interface. J Biol Chem. 2011;286:36478-91.

7. Kvarnstrom M, Dzikaite-Ottosson V, Ottosson L, et al. Autoantibodies to the functionally active RING-domain of Ro52/SSA are associated with disease activity in patients with lupus. Lupus. 2013;22:477-85.

8. Popovic K, Nyberg F, Wahren-Herlenius M, Nyberg F. A serology-based approach combined with clinical examination of $125 \mathrm{Ro} / \mathrm{SSA}$-positive patients to define incidence and prevalence of subacute cutaneous lupus erythematosus. Arthritis Rheum. 2007:56:255-64.

9. Whitacre CC. Sex differences in autoimmune disease. Nat Immunol. 2001;2:777-80.

10. Kvarnstrom M, Ottosson V, Nordmark B, Wahren-Herlenius M. Incident cases of primary Sjogren's syndrome during a 5-year period in Stockholm County: a descriptive study of the patients and their characteristics. Scand J Rheumatol. 2015:44:135-42

11. Qin B, Wang J, Yang Z, et al. Epidemiology of primary Sjogren's syndrome: a systematic review and meta-analysis. Ann Rheum Dis. 2015;74:1983-9.

12. Absher DM, Li X, Waite LL, et al. Genome-wide DNA methylation analysis of systemic lupus erythematosus reveals persistent hypomethylation of interferon genes and compositional changes to CD4+ T-cell populations. PLoS Genet. 2013;9:e1003678.

13. Greer JM, McCombe PA. The role of epigenetic mechanisms and processes in autoimmune disorders. Biologics. 2012:6:307-27.

14. Inoshita M, Numata S, Tajima A, et al. Sex differences of leukocytes DNA methylation adjusted for estimated cellular proportions. Biol Sex Differ. 2015;6:11.

15. Fish EN. The X-files in immunity: sex-based differences predispose immune responses. Nat Rev Immunol. 2008:8:737-44.

16. Seminog $O O$, Seminog $A B$, Yeates $D$, Goldacre MJ. Associations between Klinefelter's syndrome and autoimmune diseases: English national record linkage studies. Autoimmunity. 2015;48:125-8.

17. Kovats $\mathrm{S}$. Estrogen receptors regulate innate immune cells and signaling pathways. Cell Immunol. 2015;294:63-9.

18. McMurray RW, May W. Sex hormones and systemic lupus erythematosus: review and meta-analysis. Arthritis Rheum. 2003;48:2100-10.
19. Porola $P$, Laine $M$, Virkki L, Poduval $P$, Konttinen $Y T$. The influence of sex steroids on Sjogren's syndrome. Ann N Y Acad Sci. 2007:1108:426-32.

20. Rieger $\mathrm{R}$, Leung PS, Jeddeloh MR, et al. Identification of 2-nonynoic acid, a cosmetic component, as a potential trigger of primary biliary cirrhosis. J Autoimmun. 2006:27:7-16

21. Selmi C, Lu Q, Humble MC. Heritability versus the role of the environment in autoimmunity. J Autoimmun. 2012;39:249-52.

22. Aranow C, Del Guidice J, Barland P, Weinstein A. Systemic lupus erythematosus disease severity in men and women: a case-control study. J Rheumatol. 2002;29:1674-7.

23. Garcia MA, Marcos JC, Marcos Al, et al. Male systemic lupus erythematosus in a Latin-American inception cohort of 1214 patients. Lupus. 2005;14:938-46.

24. Molina JF, Drenkard C, Molina J, et al. Systemic lupus erythematosus in males. A study of 107 Latin American patients. Medicine (Baltimore). 1996;75:124-30

25. Soto ME, Vallejo M, Guillen F, et al. Gender impact in systemic lupus erythematosus. Clin Exp Rheumatol. 2004:22:713-21.

26. Voulgari PV, Katsimbri P, Alamanos Y, Drosos AA. Gender and age differences in systemic lupus erythematosus. A study of 489 Greek patients with a review of the literature. Lupus. 2002;11:722-9.

27. Crosslin $\mathrm{KL}$, Wiginton $\mathrm{KL}$. Sex differences in disease severity among patients with systemic lupus erythematosus. Gend Med. 2011;8:365-71.

28. Andrade RM, Alarcon GS, Fernandez $M$, et al. Accelerated damage accrual among men with systemic lupus erythematosus: XLIV. Results from a multiethnic US cohort. Arthritis Rheum. 2007;56:622-30.

29. Manger $K$, Manger $B$, Repp $R$, et al. Definition of risk factors for death, end stage renal disease, and thromboembolic events in a monocentric cohort of 338 patients with systemic lupus erythematosus. Ann Rheum Dis. 2002;61:1065-70.

30. Hussein $H$, Lee $P$, Chau $C$, Johnson SR. The effect of male sex on survival in systemic sclerosis. J Rheumatol. 2014;41:2193-200.

31. Bergamaschi R. Prognostic factors in multiple sclerosis. Int Rev Neurobiol. 2007;79:423-47

32. Anaya JM, Liu GT, D'Souza E, et al. Primary Sjogren's syndrome in men. Ann Rheum Dis. 1995;54:748-51.

33. Brennan MT, Fox PC. Sex differences in primary Sjogren's syndrome. J Rheumatol. 1999;26:2373-6.

34. Cervera R, Font J, Ramos-Casals M, et al. Primary Sjogren's syndrome in men: clinical and immunological characteristics. Lupus. 2000;9:61-4.

35. Diaz-Lopez C, Geli C, Corominas H, et al. Are there clinical or serological differences between male and female patients with primary Sjogren's syndrome? J Rheumatol. 2004;31:1352-5.

36. Drosos AA, Tsiakou EK, Tsifetaki N, Politi EN, Siamopoulou-Mavridou A Subgroups of primary Sjogren's syndrome. Sjogren's syndrome in male and paediatric Greek patients. Ann Rheum Dis. 1997;56:333-5.

37. Gondran $G$, Fauchais A, Lambert M, et al. Primary Sjogren's syndrome in men. Scand J Rheumatol. 2008:37:300-5.

38. Molina R, Provost TT, Arnett FC, et al. Primary Sjogren's syndrome in men. Clinical, serologic, and immunogenetic features. Am J Med. 1986; $80: 23-31$

39. Horvath IF, Szodoray P, Zeher M. Primary Sjogren's syndrome in men: clinical and immunological characteristic based on a large cohort of Hungarian patients. Clin Rheumatol. 2008:27:1479-83.

40. Vitali C, Bombardieri S, Jonsson R, et al. Classification criteria for Sjogren's syndrome: a revised version of the European criteria proposed by the American-European Consensus Group. Ann Rheum Dis. 2002;61:554-8

41. Seror R, Ravaud P, Bowman SJ, et al. EULAR Sjogren's syndrome disease activity index: development of a consensus systemic disease activity index for primary Sjogren's syndrome. Ann Rheum Dis. 2010;69:1103-9.

42. Hassan AB, Lundberg IE, Isenberg D, Wahren-Herlenius M. Serial analysis of Ro/SSA and La/SSB antibody levels and correlation with clinical disease activity in patients with systemic lupus erythematosus. Scand J Rheumatol. 2002;31:133-9.

43. Oke V, Vassilaki I, Espinosa A, et al. High Ro52 expression in spontaneous and UV-induced cutaneous inflammation. J Invest Dermatol. 2009;129: 2000-10.

44. Salomonsson S, Dorner T, Theander E, et al. A serologic marker for fetal risk of congenital heart block. Arthritis Rheum. 2002:46:1233-41.

45. Theander E, Brucato A, Gudmundsson S, et al. Primary Sjogren's syndrometreatment of fetal incomplete atrioventricular block with dexamethasone. J Rheumatol. 2001;28:373-6. 
46. Garcia-Carrasco M, Mendoza-Pinto C, Jimenez-Hernandez C, et al. Serologic features of primary Sjogren's syndrome: clinical and prognostic correlation. Int J Clin Rheumtol. 2012;7:651-9.

47. Mathews PM, Hahn S, Hessen M, et al. Ocular complications of primary Sjogren syndrome in men. Am J Ophthalmol. 2015;160:447-52. e1.

48. Boitiaux JF, Debray MP, Nicaise-Roland P, et al. Idiopathic interstitial lung disease with anti-SSA antibody. Rheumatology (Oxford). 2011;50:2245-50.

49. Ghillani P, Andre C, Toly C, et al. Clinical significance of anti-Ro52 (TRIM21) antibodies non-associated with anti-SSA $60 \mathrm{kDa}$ antibodies: results of a multicentric study. Autoimmun Rev. 2011;10:509-13.

Submit your next manuscript to BioMed Central and we will help you at every step:

- We accept pre-submission inquiries

- Our selector tool helps you to find the most relevant journal

- We provide round the clock customer support

- Convenient online submission

- Thorough peer review

- Inclusion in PubMed and all major indexing services

- Maximum visibility for your research

Submit your manuscript at www.biomedcentral.com/submit 